Classification

Physics Abstracts

07.05.Pj - 42.30.Va

\title{
Classification of Chitinozoa (Llandoverian, Canada) Using Image Analysis
}

\author{
Éric P. Verrecchia $\left({ }^{1}\right)$, Geert Van Grootel $\left({ }^{2}\right)$ and Gérard Guillemet $\left({ }^{3}\right)$ \\ $\left({ }^{1}\right)$ UMR 5561 CNRS, Paléontologie Analytique et Géologie Sédimentaire, Université de Bourgogne, \\ 6 boulevard Gabriel, 21000 Dijon, France \\ $\left({ }^{2}\right)$ Laboratorium voor Paleontologie, Geologisch Instituut, Universiteit Gent, Krijgslaan 281, S8, \\ 9000 Gent, Belgium \\ $\left({ }^{3}\right)$ ER 109 CNRS, Géomorphologie et Transferts de Surface, 24 rue des Tilleuls, 14000 Caen, France
}

\begin{abstract}
Résumé. - Des Chitinozoaires (Llandovérien, Canada) ont été étudiés par analyse d'images. Après numérisation des objets, des paramètres de forme ont été calculés. Chaque fossile a ensuite fait l'objet d'une décomposition de son profil pour une transformée de Fourier rapide (FFT). Les résultats des deux méthodes ont fait l'objet d'une classification ascendante hiérarchique afin de grouper ensemble les individus. La classification obtenue montre que l'analyse d'images offre un excellent instrument d'étude biométrique des Chitinozoaires à des fins de taxonomie.
\end{abstract}

\begin{abstract}
Chitinozoa (Llandoverian, Canada) were studied using image analysis. After digitalization of the objects, shape parameters were calculated. The boundary of each fossil was then traced by a vector centred at the centroid for Fast Fourier Transform (FFT). Results of the two methods were used as variables in a hierarchical cluster analysis in order to group the samples. These results show that Chitinozoa can be significantly classified in terms of taxa using independent shape parameters obtained by image analysis.
\end{abstract}

\section{Introduction}

Chitinozoa are organic-walled, planktonic, marine microfossils (Fig. 1). They range in age from Lower Ordovician to Devonian and are found in a variety of marine sedimentary rocks. Due to their abundance, rapid evolution and global distribution of important taxa, Chitinozoa are a valuable biostratigraphical marker. Endemic taxa are useful for paleobiogeographical reconstructions. Biozonations exist for Gondwana [1], north east Laurentia [2] and Baltica [3] during the Ordovician and a global zonation has been proposed for the Silurian [4]. The biological affinities of the Chitinozoa are not known precisely, but most authors do favor the hypothesis of a reproductive stage of Metazoa. In consequence, the classification generally in use today is the morphological parataxonomy of Paris [5]. Herein, two orders are distinguished, based 

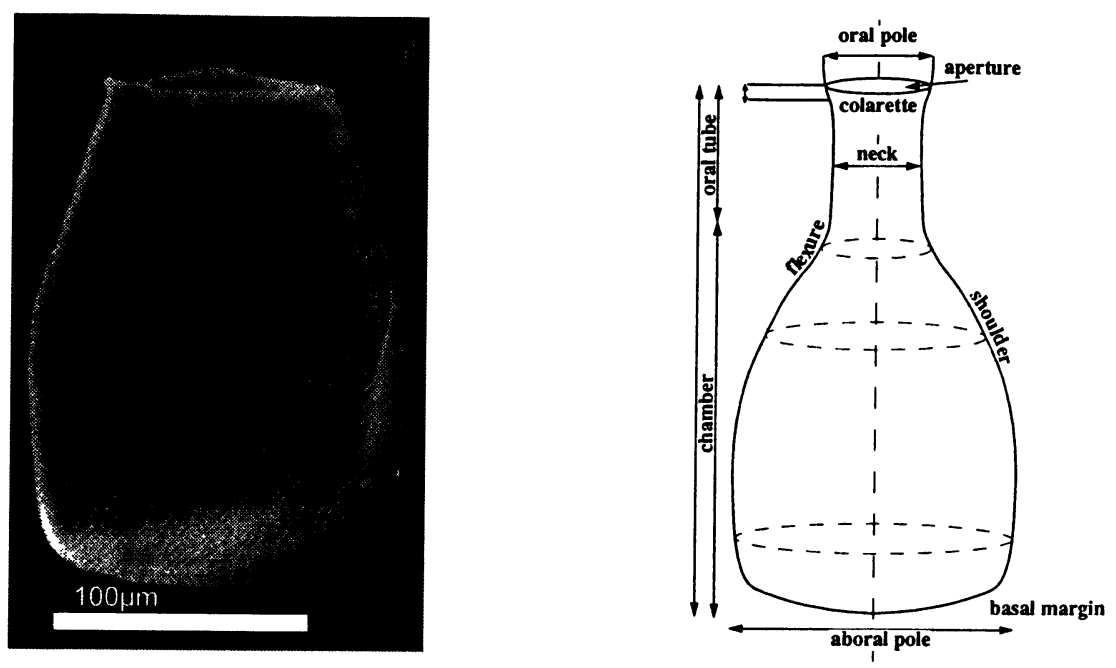

Fig. 1. - Left: example of a Chitinozoa shape: Eisenackitina dolioliformis, Steenkerke 50E-134 borehole section, $-307 \mathrm{~m} 75$, Brabant Massif, Belgium. Right: outline silhouette of a generic Chitinozoa with the most important morphological features. Arrows indicate the most common biometrical parameters.

on the functional interpretation of the sealing structure of the neck: operculum or prosome. The other supra-generic classification criteria are based on an implicit hierarchy of characteristics: presence or absence of a neck for the family level, external structures for the sub-family level and the shape of the chamber and arrangement of the ornamentation for the generic level. All Chitinozoa have a radial-axial symmetry and are therefore glass-, bottle- or jar-shaped. Species belonging to genera with or without uniform ornamentation are essentially distinguished by the shape of their silhouette.

The specimens were selected from an image catalog made from the paleontological treatment of eight sedimentary samples (\#182-186, 188, 194 and 198; see [6] for locations and precise stratigraphic positions), collected throughout "Member 3" and in the lower part of "Member 4" of the Jupiter Formation (Middle Llandoverian, Early Silurian) on Anticosti Island, Canada. This assemblage contains a variety of species belonging to the alargada and dolioliformis Chitinozoazones of Verniers et al. [4], Middle Aeronian to Basal Telychian, Llandovery. The Chitinozoa species in the assemblage only belong to three genera: Ancyrochitina, Cyathochitina, and Conochitina. The first two genera have a characteristic ornamentation: Ancryochitina has long appendices on the basal margin and Cyathochitina has a basal carena, whereas the last genus Conochitina has no ornamentation at all. Some of the species show a high degree of intraspecific variability, and several species within the same genus are morphologically closely related. This study was carried out on the assemblage, without the introduction of any taxonomical data.

The biometric parameters (Fig. 1) used in Chitinozoa studies are limited to a small number of different length measurements on the vesicle, which are mainly used to illustrate the intraspecific variability and less so for inter-specific discrimination. Therefore, the aim of this study is to propose quantitative criteria obtained by image analysis as an objective tool for the biometrical and taxonomical study of Chitinozoa. 


\section{Methods}

In the image catalog, the specimens appear as dark to black features separated by white spaces. The Chitinozoa profile is acquired by a video camera connected to a frame grabber card. The quality of the acquisition is checked on a control video screen. The digitalized profile is displayed on a Quantimet 520 (QTM) screen. The picture is composed by $512 \times 512$ pixels, in 256 grey levels. All of the acquisitions were made at the same magnification and light level. The raw digitalized Chitinozoa, which will be used for further treatments, is extracted after detection and thresholding of the grey image. Each specimen is cleaned by a closing operation. One hundred and twenty four specimens were digitalized and prepared for measurements using the QTM. In the first step, six morphometric parameters were measured on each Chitinozoa $(\mathrm{X})$ : area $[A(\mathrm{X})]\left({ }^{1}\right)$, perimeter $\left[L_{2}(\mathrm{X})\right]$, height $\left[D_{\mathrm{f}(\pi / 2)}\right.$ - Feret diameter at $\pi / 2$ rd], width $\left[D_{\mathrm{f}(0)}-\right.$ Feret diameter at 0 rd], length [ $D_{\mathrm{f}(\max )}$ - maximum Feret diameter] and breadth [ $D_{\mathrm{f}(\min )}$ - minimum Feret diameter]. Using these parameters, three morphometric indices were calculated [7]:

- the form factor, $F(\mathrm{X})=\frac{4 \pi A(\mathrm{X})}{L_{2}(\mathrm{X})^{2}}$

- the lengthening index, $I A_{\mathrm{r}}(\mathrm{X})=\frac{D_{\mathrm{f}(\min )}(\mathrm{X})}{D_{\mathrm{f}(\max )}(\mathrm{X})}$

- the ratio of the inscribed circle to the corresponding surface, $I R_{\mathrm{a}}(\mathrm{X})=\frac{\pi\left(D_{\mathrm{f}(\min )}(\mathrm{X})^{2}\right)}{A(\mathrm{X})}$.

Together with the six morphometric parameters, they define the parameters used to characterize the Chitinozoa shape. Although these parameters should be good general descriptors of the shape and dimensions of Chitinozoa, they do not provide precise data on small variations of the organism's contour. In order to get more information on the Chitinozoa shape, the contour has been studied using harmonic analysis: the Fast Fourier Transform (FFT) [7-9]. Fourier analysis has already been used a few times to classify paleontological objects such as Ostracodes [10], Bryozoans [11], Foraminiferas [12] and Brachiopods [13].

Profiles digitalized with the QTM are redrawn using an executable Quick Basic 4.5 program, which transforms the contours into a function allowing the Fourier analysis: the shape of Chitinozoa is traced by a vector centered at the object centroid (calculated from object profile coordinates) and rotating anticlockwise to point to 128 points of the boundary, with an interspacing of $128 / 2 \pi$ rd (Fig. 2a). The successive radius vectors are then plotted versus the angle turned to obtain a function. This profile is plotted in Cartesian coordinates, giving the "signal" of each Chitinozoa, which is the opened profile (Fig. 2b). The executable program in QB gives the 128 values of the angles, the vector radius and the amplitude of the first 20 harmonics after FFT is performed (Fig. 2c).

In order to classify the samples, a hierarchical cluster analysis was used, grouping together the samples which most resemble each other. Ward's method was selected, which uses the Euclidian distance between two clusters as the sum of squares between two clusters summed over all the variables. The various parameters were used as variables for three different cluster analyses of Chitinozoa with only 1) parameters, 2) the first twenty harmonics, 3) both parameters and harmonics.

$\left({ }^{1}\right)$ Notation used is the one recommended by the International Stereology Society (see [7] pp. 513-543). 


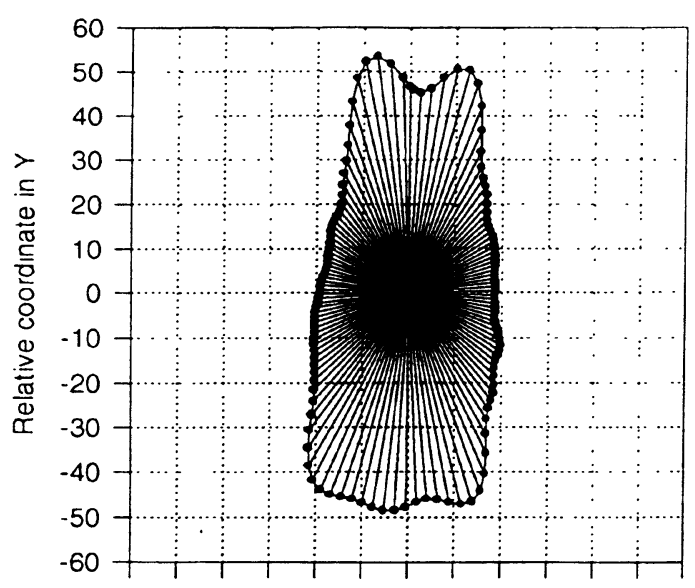

a)

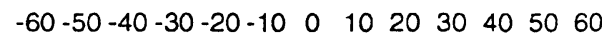

Relative coordinate in $\mathrm{x}$
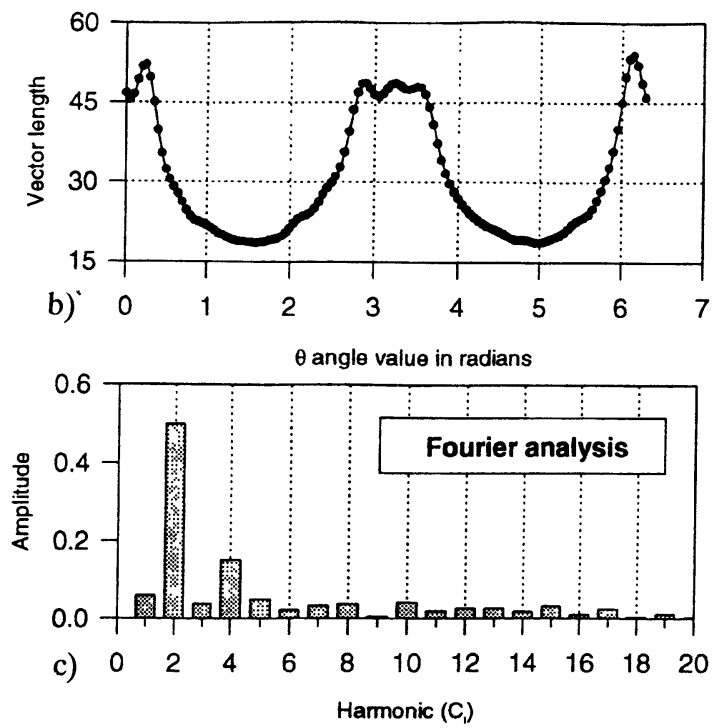

Fig. 2. - a) Boundary of Chitinozoa traced by 128 vectors centered at the object centroid. The vectors are generated step by step during anticlockwise rotation equal to $\pi / 128 \mathrm{rd}$. Therefore the length of the radius vector is recorded as a function of the angle turned. b) When plotted in a Cartesian coordinate system, the contour is opened and builds a function or a signal specific for each specimen. c) Fourier analysis is applied to this signal giving twenty harmonics and their corresponding amplitudes: this analysis results in a signature of the Chitinozoa morphology.

\section{Results and Discussion}

The first cluster analysis resulted in 18 classes, grouping individuals with an apparent high degree of consistency, even if the distinction between certain classes is taxonomically meaningless sometimes. As an illustration of the classification, a particular specimen (C2) is compared with its two closest neighbours (the same specimen will be used for the two other clusterings in order to compare the accuracy of the automatic classification in each case). In the first classification, C2 belongs to a class of 6 individuals and constitutes an extreme of the class, its right hand neighbour belonging to another class of 5 individuals (Fig. 3a). In general, the classification using parameters gives good results compared with the paleontological grouping, although a certain number of specimens were grouped in a taxonomically incorrect position.

The results of the Fourier transform method show that most of the morphological information is hidden in the first eight harmonics. These harmonics have been used in the cluster analysis as variables. The clustering of Chitinozoa using the amplitudes of the various harmonics resulting from the Fourier transform gave 11 classes showing good coherence of forms inside a class and a significant interclass differentiation. Nevertheless, a few taxonomically remotely related specimens were placed together. In addition, the Fourier transform is not an appropriate tool for grouping individuals of comparable sizes: the shape being the best descriminating criteria, Chitinozoa having similar morphology were agglomerated regardless of size (Fig. 3b). Nevertheless, FFT is a powerful tool to characterize the shape, which is the most significative characteristic of Chitinozoa. 


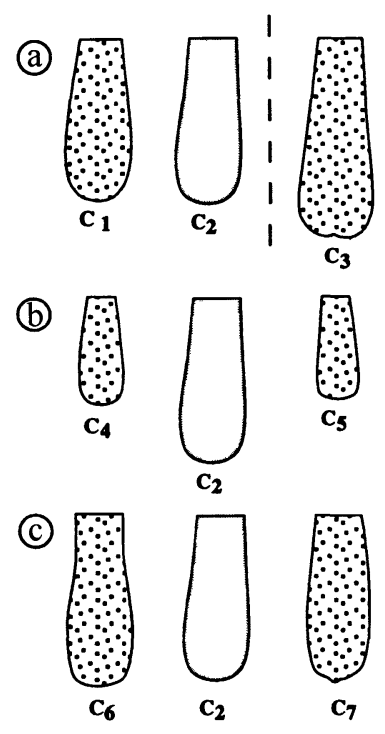

Fig. 3. - Comparison of Chitinozoa $\mathrm{C} 2$ with its closest neighbours in three cluster analysis using: a) parameters, b) the eight first harmonic amplitudes after FFT treatment, and c) both A and B as variables. In (a), the dotted line symbolizes a class change. In (b), the classification is obvious regardless of the size, but the shapes $\mathrm{C} 4, \mathrm{C} 2$ and $\mathrm{C} 5$ are strikingly similar.

To conclude, cluster analysis on the results of the shape factors and the Fourier transform separately showed a reasonably good coherence in the classification of the silhouettes. But this classification was divergent from the Chitinozoa taxonomy. Specimens within the three genera were sometimes grouped together.

The third cluster analysis was performed using 14 variables resulting from the sum of variables of the preceding treatment. Eight classes were obtained with the combined parameters which showed a very high consistency with the taxonomical grouping of specimens (Fig. 3c). Only very few specimens were agglomerated together with taxonomically unrelated ones, but they belonged to two species of different genera. The clusters were almost monospecific within the classes of specimens belonging to the non-ornamented genus Conochitina.

\section{Conclusions}

The use of image analysis for biometrical studies is a very valuable aid for the paleontologist because it allows quick and routine analysis, and acquisition of quantitative data which can be explored with statistical tools. In addition, the new biometrical parameters used in this paper are more objective than the ones traditionally used in other Chitinozoa studies. The results reported here are very promising: the 14 independent morphometric variables provided an excellent tool for biometrical studies. They are of considerable use to check and/or adjust the classification of Chitinozoa (especially for these genera) which, apart from their overall shape, have few other morphological characteristics to discriminate the species level. This case study demonstrates the great interest of image analysis in differentiating and classifying very similar fossil objects using shape investigations. 


\section{Acknowledgements}

EPV worked on image analysis of Chitinozoa during a post-doctoral year at Ghent University funded by an EEC grant ( ${ }^{\circ}$ ERB4001GT931740). Two anonymous reviewers are acknowledged for their constructive comments on the manuscript.

\section{References}

[1] Paris F., The Ordovician Chitinozoa biozones of the Northern Gondwana domain, Rev. Palaeobot. Palynol. 66 (1990) 181-209.

[2] Achab A., Ordovician Chitinozoa zonation of Quebec and Western Newfoundland, J. Paleontol. 63 (1989) 14-24.

[3] Nolvak J. and Grahn Y., Ordovician chitinozoazones from Baltoscandia, Rev. Palaeobot. Palynol. 79 (1993) 245-269.

[4] Verniers J., Nestor V., Paris F., Dufka P., Sutherland S. and Van Grootel G., A global Chitinozoa biozonation for the Silurian, Geol. Mag. 132 (1995) 651-666.

[5] Paris F., Les Chitinozoaires dans le Paléozoïque du Sud-ouest de l'Europe, Mémoire de la Société Géologique et Minéralogique de Bretagne 26 (1981).

[6] Achab A., Biostratigraphie par les Chitinozoaires de l'Ordovician supérieur-Silurien inférieur de l'Ile d'Anticosti, resultats préliminaires, "Subcommission on Silurian stratigraphy", Ordovician-Silurian Boundary Working Group. Field Meeting, Anticosti-Gaspé, Stratigraphy and Paleontology, P.J. Lespérance, Ed., Vol. II (1981) 143-157.

[7] Coster M. and Chermant J.-L., Précis d'analyse d'images (Les Presses du CNRS, Paris, 1989); Kaye B.H., Proc. of Conf. on Particle Size Analysis, Univ. Salford, M.J. Groves, Ed. (Analytical Div. Chemical Soc., 1977) p. 250.; Chermant J.-L. and Coster M., Analyse de la forme, Sci. Geol. Bull. 46 (1993) 45.

[8] Schwarz H.P. and Shane K.C., Measurement of particle shape by Fourier analysis, Sedimentology 13 (1969) 213-231.

[9] Ehrlich R. and Weinberg B., An exact method for characterization of grain shape, J. Sedim. Petrol. 40 (1970) 205-212.

[10] Kaesler R.L. and Waters J.A., Fourier analysis of the Ostracode margin, Geol. Soc. Amer. Bull. 83 (1972) 1169-1178.

[11] Anstey R.L. and Delmet D.A., Fourier analysis of zooecial shapes in fossil tubular Bryozoans, Geol. Soc. Amer. Bull. 84 (1973) 1753-1764.

[12] Healy-Williams N., Fourier shape analysis of Globorotalia truncatulinoides from Late Quaternary sediments in the Southern Indian Ocean, Marine Micropal. 8 (1983/84) 1-15.

[13] Tort A., Structure morphologique des espèces du genre Stenosarina (Brachiopoda, NouvelleCalédonie): Caractérisation et comparaison des formes par tranformées de Fourier et morphométrie géométrique, Mémoire de DEA de l'Université de Bourgogne, UMR 5561 CNRS (1996). 